\title{
In Situ Detection of Species Relevant to the Carbon Cycle in Seawater with Submersible Potentiometric Probes
}

\author{
Maria Cuartero, ${ }^{*},{ }^{\dagger}$ Nadezda Pankratova, ${ }^{\dagger}$ Thomas Cherubini, ${ }^{\dagger}$ Gaston A. Crespo, ${ }^{\dagger, \|}$ Francesco Massa, ${ }^{\ddagger}$ \\ Fabio Confalonieri, ${ }^{\S}$ and Eric Bakker* ${ }^{*} \dagger$ \\ ${ }^{\dagger}$ Department of Inorganic and Analytical Chemistry, University of Geneva, Quai Ernest-Ansermet 30, CH-1211 Geneva, Switzerland \\ ${ }^{\ddagger}$ Department of Earth, Environment and Life Sciences, University of Genoa, C.so Europa 26, 16132 Genoa, Italy \\ ${ }^{\S}$ Idronaut, Via Monte Amiata 10, 20861 Brugherio, MB, Italy
}

\section{Supporting Information}

ABSTRACT: We report on the development of a submersible probe for the simultaneous potentiometric detection of carbonate, calcium, and $\mathrm{pH}$ in seawater. All-solid-state electrodes incorporating nanomaterials provide an adequate response time $(<10 \mathrm{~s})$, stability (drifts of $<0.9 \mathrm{mV} \mathrm{h}^{-1}$ ), reproducibility (calibration parameter deviation of $<0.7 \%$ ), and accuracy (deviation of $<8 \%$ compared to reference techniques) for realtime monitoring of seawater using a flow system. The functioning of the deployable prototype was checked in an outdoor mesocosm and via long-term monitoring in Genoa Harbor. The electrodes worked properly for 3 weeks, and the system demonstrated the capability to autonomously operate with routines for repetitive measurements, data storage, and management. In situ profiles observed in Genoa Harbor and Arcachon Bay were validated using on site and ex situ techniques. The validation of in situ-detected carbonate is a challenge because both re-equilibration of the sample with atmospheric $\mathrm{CO}_{2}$ and the use of apparent thermodynamic constants for speciation calculations lead to some differences ( $<20 \%$ deviation). The submersible probe is a promising tool for obtaining rapid and trustworthy information about chemical levels in marine systems. Moreover, the fluidic approach allows for the integration of other ion sensors that may require sample pretreatment.

\section{INTRODUCTION}

The accurate measurement of the carbonate system in seawater is urgently important for the study of ocean acidification caused by the absorption of anthropogenically emitted $\mathrm{CO}_{2}{ }^{1-4}$ Because the concentrations of the associated chemical species, $\mathrm{CO}_{2}, \mathrm{pH}$, $\mathrm{HCO}_{3}{ }^{-}$, and $\mathrm{CO}_{3}{ }^{2-}$, are interconnected by thermodynamic constants, the carbonate system can in principle be described from the measurement of just two of the four species. ${ }^{5}$ The choice depends on the performance of the available analytical techniques, including the possible implementation of in situ monitoring in the aquatic system of interest. Additionally, the quantification of dissolved calcium is related to the carbon cycle as calcium is involved in carbonate precipitation/dissolution processes and its monitoring may contribute to a more complete description of the marine system. ${ }^{6,7}$

With $\mathrm{pH}$ values frequently measured in seawater using deployable glass electrodes, $\mathrm{HCO}_{3}{ }^{-}$and $\mathrm{CO}_{3}{ }^{2-}$ are commonly calculated from total inorganic carbon or total alkalinity together with the $\mathrm{pH}$ after sampling, and $\mathrm{CO}_{2}$ is detected as $\mathrm{pCO}_{2}$ using different submersible probes that often require $\mathrm{CO}_{2}$ to be in the gas phase. ${ }^{8,9} \mathrm{pCO}_{2}$ measurement techniques for in situ observations has been reviewed recently, including a discussion

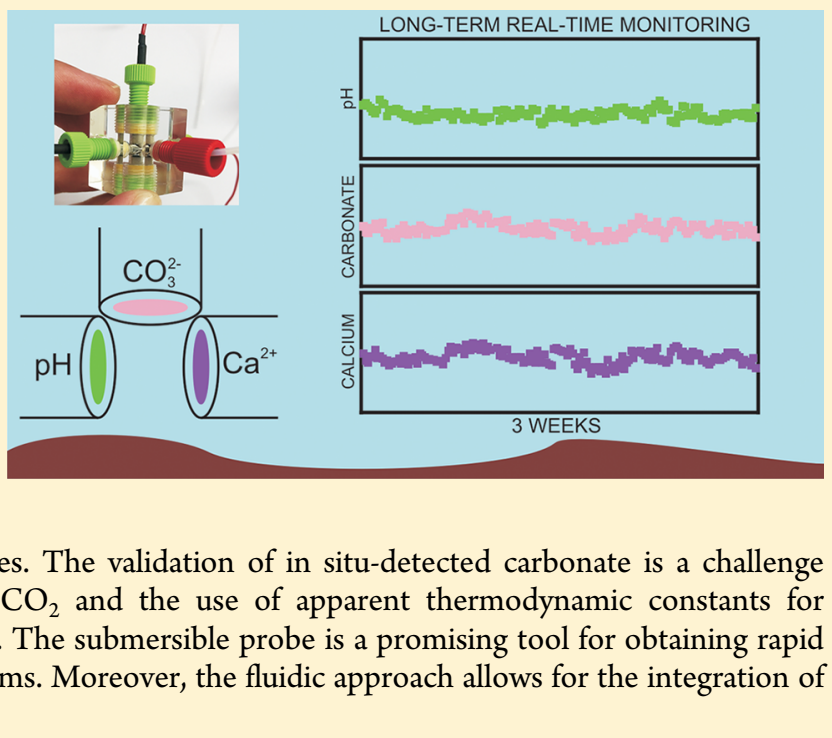

of advantages and disadvantages of the existing approaches as well as the most promising concepts. ${ }^{10}$ Accordingly, (i) nondispersive infrared spectroscopy (NDIR) $\mathrm{pCO}_{2}$ sensors constitute the most used technique for in situ measurements, but frequent recalibrations are needed. (ii) $\mathrm{CO}_{2}$ sensors based on the Severinghaus principle exhibit reduced sensitivity, a slow response time, and an unstable signal at environmental $\mathrm{pH}$ $(\sim 8.0)$; therefore, their in situ application is not advisable. ${ }^{11-13}$ (iii) $\mathrm{pCO}_{2}$ optodes are still in the early stages of development, exhibiting slow response times, salinity dependence, and poor stability, which must be improved before their implementation in submersible probes.

In situ performance of the techniques for the analysis of carbonate species is especially significant. They provide spatial and temporal resolution much higher than that of centralized approaches. ${ }^{14}$ Moreover, the manipulation of the sample during sampling, transport, and measuring procedures may dramatically

Received: September 1, 2017

Revised: $\quad$ September 27, 2017

Accepted: September 28, 2017

Published: September 28, 2017 
modify its integrity by re-equilibration of the aquatic sample with the atmospheric $\mathrm{CO}_{2}$ level that is very different from the in situ value, thus providing biased results. ${ }^{5,15-17}$ To avoid this, the samples must be kept out of air contact during manipulation and analysis, which is very difficult. Consequently, the most robust solution would involve in situ measurement. Unfortunately, not all analytical techniques and required sample pretreatment steps are suitable for this goal.

An alternative approach is the use of all-solid-state ionselective electrodes, which offer promising characteristics for in situ implementation, ${ }^{18,19}$ for the detection of either $\mathrm{HCO}_{3}{ }^{-}$or $\mathrm{CO}_{3}{ }^{2-}$. While assessment of $\mathrm{HCO}_{3}{ }^{-}$in marine systems cannot yet be achieved by direct potentiometry because of the high hydrophilicity of the anion and the lack of selective ionophores, ${ }^{20}$ carbonate-selective electrodes based on $N, N$-dioctyl-3 $\alpha, 12 \alpha$ bis(4-trifluoroacetylbenzoyloxy)-5 $\beta$-cholan-24-amide have been satisfactorily applied for carbonate detection in freshwater and buffered marine samples ${ }^{21-23}$ and are promising for seawater analysis. Even if in situ detection is achieved, the validation of the sensors is challenging. Any reference technique requires sampling and/or indirect calculation of the species concentration using the thermodynamic constants mentioned above. The latter are not universally accepted as their apparent values strongly depend on environmental factors (i.e., salinity and temperature) and are therefore a possible source of error. ${ }^{24-27}$

We present here a new submersible potentiometric probe for the long-term real-time detection of $\mathrm{pH}$, carbonate, and calcium in seawater. A potentiometric flow cell based on miniaturized allsolid-state sensors is developed for this purpose. The flow cell is incorporated into a deployable device offering autonomous operation and the compensation of temporal effects in the electrode responses by intermittent single-point calibration steps. The system was deployed in Mediterranean and Atlantic coastal waters near Genoa (Italy) and Arcachon (France), respectively. The probes were validated with traditional sampling techniques.

\section{EXPERIMENTAL SECTION}

Preparation of Membrane-Based Ion-Selective Electrodes. Commercial glassy carbon macroelectrodes (GCelectrode-tip, 6.1204.300, Metrohm) and miniaturized handmade glassy carbon electrodes (see the Supporting Information and Figure S1a for the fabrication) were modified with functionalized multiwalled carbon nanotubes (f-MWCNTs) in a manner analogous to that described previously. ${ }^{22}$ Briefly, a film of the nanomaterial was deposited on top of each electrode by drop casting $8 \times 20 \mu \mathrm{L}$ (for macroelectrodes) or $5 \times 5 \mu \mathrm{L}$ (for miniaturized electrodes) of a f-MWCNT solution in tetrahydrofuran $\left(1 \mathrm{mg} \mathrm{mL}^{-1}\right)$, and each layer was allowed to dry for 10 min before the next layer was deposited. Then, the corresponding membrane cocktail (see the Supporting Information) was drop casted on the top of the f-MWCNT film (5 $\times 50$ or $4 \times 10 \mu \mathrm{L}$ ), and each layer was allowed to dry for $20 \mathrm{~min}$. Finally, the electrodes were conditioned overnight $(\sim 12 \mathrm{~h})$ as detailed in the Supporting Information. Once the sensors were ready, they were added to the flow cell and finally into the submersible device.

Submersible Device for in Situ Potentiometric Measurements in Seawater. Figure 1a shows the flow cell developed for the in situ potentiometric measurements. It consisted of a cubic acrylic block $(25 \mathrm{~mm} \times 25 \mathrm{~mm} \times 25 \mathrm{~mm})$ incorporating single drilled holes: two on opposite sides for the inlet and outlet, one for a reference electrode fabricated in
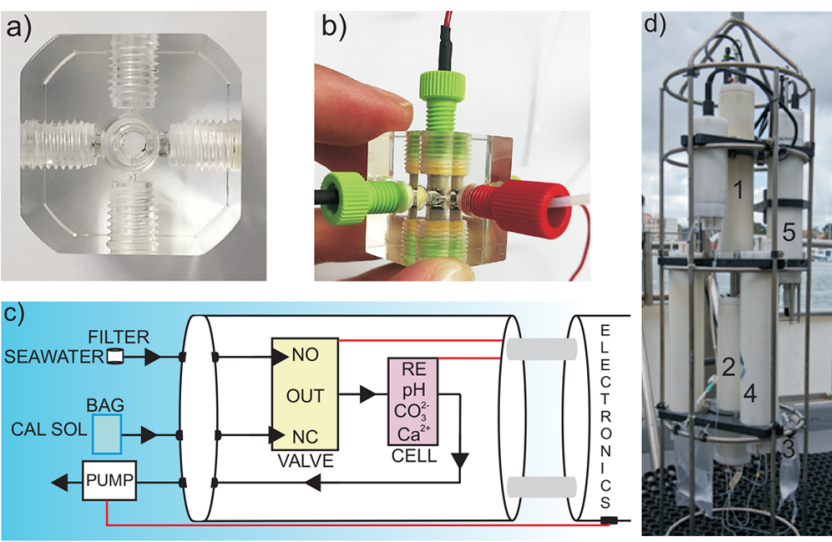

Figure 1. Images of (a) the designed potentiometric flow cell and (b) the assembled flow cell incorporating the electrodes, inlet, and outlet. (c) Developed fluidics for the in situ potentiometric measurements. The pump draws either filtered seawater or the calibration solution according to the valve position (NO, normally open; NC, normally closed), whose outlet (OUT) is connected to the potentiometric flow cell. (d) The submersible probe is implemented in a titanium cage containing other modules as well as the pump: (1) electronics, (2) potentiometric cell, (3) bag for calibration, (4) pump, and (5) CTD.

house, ${ }^{28}$ and three other holes for miniaturized potentiometric electrodes. In this manner, the inlet, outlet, and electrodes were concentrically placed around an inner chamber of the cell $(20 \mu \mathrm{L}$ volume) in which the sample flowed (see Figure 1b). Figure 1c shows the fluidics of the submersible device, which uses a twoposition valve (supplied by Idronaut) that allows the detection of either a calibration solution (pumped in from an external bag) or the seawater sample. This detection part was placed into a waterand pressure-proof cylindrical housing and connected to external fluidics driven by a submersible peristaltic pump (see the Supporting Information and Figure $S 1 b-d)$. When the pump started (flow rate of $200 \mu \mathrm{L} \mathrm{min}{ }^{-1}$ ) with the valve in the "normally close" position (NC), the "in situ calibration solution" (filtered seawater from the place where the deployment was planned) flowed from the external bag to the valve and to the acrylic detection cell and was subsequently discharged to the outside environment. In this way, the potentials of $\mathrm{pH}$, carbonate, and calcium electrodes were measured in flow mode in the calibration solution. If the valve was in the "normally open" position (NO), the cell was filled with filtered seawater from the aquatic system. During field deployment, the device was anchored to a titanium cage containing the pump and other modules such as a CTD multiparameter probe (see Figure 1d). A detailed description of the measurement protocol, temperature, and drift compensation as well as concentration calculation is given in the Supporting Information. Briefly, the electrodes were individually calibrated before the deployment using four standard solutions for each analyte. The slope $(s)$ at the environmental temperature $\left(T_{1}\right)$ and standard potential $\left(E^{0}\right)$ of each electrode was calculated. Then the potential of the three electrodes was measured in the "in situ calibration solution" $\left(E_{1}^{\mathrm{H}}\right.$, $E_{1}^{\text {carb }}$, and $\left.E_{1}^{\mathrm{Ca}}\right)$ to correct for the electrode drift. Thereafter, the device was deployed, and cyclic measurements (for instance, every hour) of first the "in situ calibration solution" and then the seawater from the aquatic system were performed. The slope of each electrode was recalculated $\left(s^{\prime}\right)$ for every measurement according to the water temperature $\left(T_{2}\right.$, measured by the CTD) using eq 1 . The standard potential was also recalculated $\left(E^{0 \prime}\right)$, and therefore, electrode drifts were compensated for every 
measurement using the recorded potentials in the calibration solution using eq 2 .

$$
\begin{aligned}
& s^{\prime}=s \frac{T_{1}}{T_{2}} \\
& E^{0 \prime}=E_{2}-\frac{T_{2}}{T_{1}}\left(E_{1}-E^{0}\right)
\end{aligned}
$$

Finally, $\mathrm{pH}$, carbonate and calcium in situ concentrations were calculated using the corrected calibration graphs (with $s^{\prime}$ and $E^{0 \prime}$ ) on the basis of potentiometry using the Nernst equation (eq 3 ):

$$
E=E^{0 \prime}+s^{\prime} \times \log \left[a_{\mathrm{I}}(\mathrm{aq})\right]
$$

where the slope is equivalent to $2.303 \times R T / z F$ ( $R$ is the gas constant, $T$ the temperature, $z$ the charge of the ion, and $F$ the Faraday constant).

\section{RESULTS AND DISCUSSION}

Characterization of All-Solid-State Potentiometric Sensors for Detection of $\mathrm{pH}$, Carbonate, and Calcium in Seawater. The analytical performances of potentiometric macroelectrodes for $\mathrm{pH}$, carbonate, and calcium were assessed in a $600 \mathrm{mM} \mathrm{NaCl}$ background (and at $\mathrm{pH} 8.1$ for carbonate and calcium) to mimic environmental conditions in seawater. Allsolid-state ion-selective electrodes (ISEs) based on carbon nanotubes were selected because they have already been demonstrated to provide robust detection of ions in environmental water. ${ }^{22,28-30}$ Calibration graphs observed for $\mathrm{pH}$, carbonate, and calcium (Figure S2) followed the common Nernstian behavior described for potentiometric sensors. ${ }^{31}$ Importantly, the linear response ranges include the expected levels for the three species in seawater (from pH 7.5 to $8.5, \sim 10^{-4}$ $\mathrm{M}$ for carbonate, and $\sim 10^{-2} \mathrm{M}$ for calcium), ${ }^{18}$ suggesting that the electrodes can be used directly for seawater analysis without any pretreatment, with a response time of $<10 \mathrm{~s}$. Other response characteristics, i.e., between-day reproducibility of the calibration parameters (Table S1), electrode drift (Table S2), and selectivity (Figure S3), were additionally evaluated to ensure the reliability of the calculation of unknown concentrations and the suitability of the sensors for long-term measurements in seawater (see the Supporting Information for more details). Although all the sensors demonstrated adequate performances in light of field measurements, even without the influence of interfering ions in the potentiometric response (Figure S3), the implementation of simple corrections of the calibration parameters (slope and standard potential) to compensate for temporal variations is desirable. These are expected because of environmental factors and/or (bio)fouling, which may provide biased results for in situ measurement. This may be performed by recalculating the electrode slopes according to observed variations in seawater temperature and repeatedly measuring the electrode potential in a calibration solution during deployment to correct the standard potential of each electrode.

The analytical performances of miniaturized handmade glassy carbon electrodes (3-fold reduced size) that are physically more suitable for the coupling to the submersible device were found to be similar to those of macroelectrodes (see Tables S1 and S2 for a more thorough comparison). The analysis of $\mathrm{pH}$, carbonate, and calcium was accomplished in different seawater samples using the macroelectrodes in batch mode, the miniaturized electrodes in flow mode (using the developed flow cell), and reference techniques (i.e., $\mathrm{pH}$-meter, $\mathrm{CO}_{2}$ probe, and atomic absorption spectroscopy, respectively) to validate the sensors (see Tables S3 and S4). Good agreement was found using the different techniques (deviations of $<8 \%$ ), confirming the ability of the designed potentiometric cell to be used for seawater analysis.

Implementation and in Situ Functioning of the Submersible Potentiometric Probes. The next step was the physical implementation of the flow potentiometric cell into the submersible device, which is based on a fluidic system allowing the detection of either a calibration solution or seawater by the sensors (Figure 1c). The system was designed to operate automatically by controlling the fluidics (submersible pump), potentiometric outputs, data recording, and managing with routines stored on board. For field deployment, the module was mounted in a titanium cage together with the pump and other modules (see Figure 1d).

To evaluate the in situ functioning of the system, it was deployed for $58 \mathrm{~h}$ in an outdoor mesocosm in Plentzia (Spain), monitoring $\mathrm{pH}$, carbonate, and calcium with the potentiometric probes simultaneously with the CTD probe. The experimental protocol for in situ measurements is described in the Supporting Information (including the correction of the calibration parameters). As shown in Figure S4, the potentiometric probes were properly measuring during the entire time. The electrodes displayed very small drifts during the $3 \mathrm{~min}$ of potentiometric measurements in both the calibration solution and the seawater $\left(<5 \mu \mathrm{V} \mathrm{min}{ }^{-1}\right)$. In addition, $\mathrm{pH}$ data were validated with the CTD measurements, showing uncertainties of $<0.15 \%$ in all cases. Later, the lifetime of the sensors during real-time measurements in seawater was evaluated during a long-term experiment conducted in Genoa Harbor (Italy) deploying the system at a depth of $4.2 \mathrm{~m}$ from a fixed platform (CNR Station). The electrodes worked satisfactorily for 3 weeks (Figure S5), displaying absolute uncertainties of $<0.001 \mathrm{pH}$ unit $(\Delta \mathrm{pH})$, $<0.002 \mathrm{mM}\left(\Delta c_{\mathrm{Carb}}\right)$, and $<0.02 \mathrm{mM}\left(\Delta c_{\mathrm{Ca}}\right)$ (calculated from the standard deviation of the recorded potentials). For a longer period of field work, it is currently advisable to replace the sensors to avoid biased results due to the deterioration of the membranes and reference electrodes. The $\mathrm{pH}$ measurements were again validated using the CTD data (uncertainties of $<0.12 \%$ without considering the first 6 days of monitoring).

Medium-Term Deployment In Genoa Harbor (Italy). In situ operation of the sensors was validated during the first $10 \mathrm{~h}$ of a $167 \mathrm{~h}$ monitoring period in Genoa Harbor by sampling and measuring on site and/or ex situ using the same procedures as in the laboratory. Linear correlations were obtained in all cases (Figures S6-S8) with uncertainties of $<0.8,<22$, and $<1.6 \%$ for $\mathrm{pH}$, carbonate concentration, and calcium concentration, respectively. While any possible bias could likely be associated with the sampling procedure, observed uncertainties are acceptable for $\mathrm{pH}$ and calcium detection, although carbonate validation requires special attention. The values observed for on site detection using macroelectrodes and the $\mathrm{CO}_{2}$ sensor were always found to be higher than those measured in situ (uncertainties of $10-15$ and $15-22 \%$, respectively), likely due to equilibration of the sample with atmospheric $\mathrm{CO}_{2}$. On the other hand, the use of the $\mathrm{CO}_{2}$ probe implies a series of calculations to obtain the carbonate concentration that are also error-prone. This behavior was previously also found by others who aimed to validate measurements of the carbonate system and reported deviations close to $50 \%$ due to the combination of all the mentioned factors. ${ }^{15,17}$

Temporal profiles observed for the entire $167 \mathrm{~h}$ period are shown in Figure 2, exhibiting minima in carbonate and calcium 

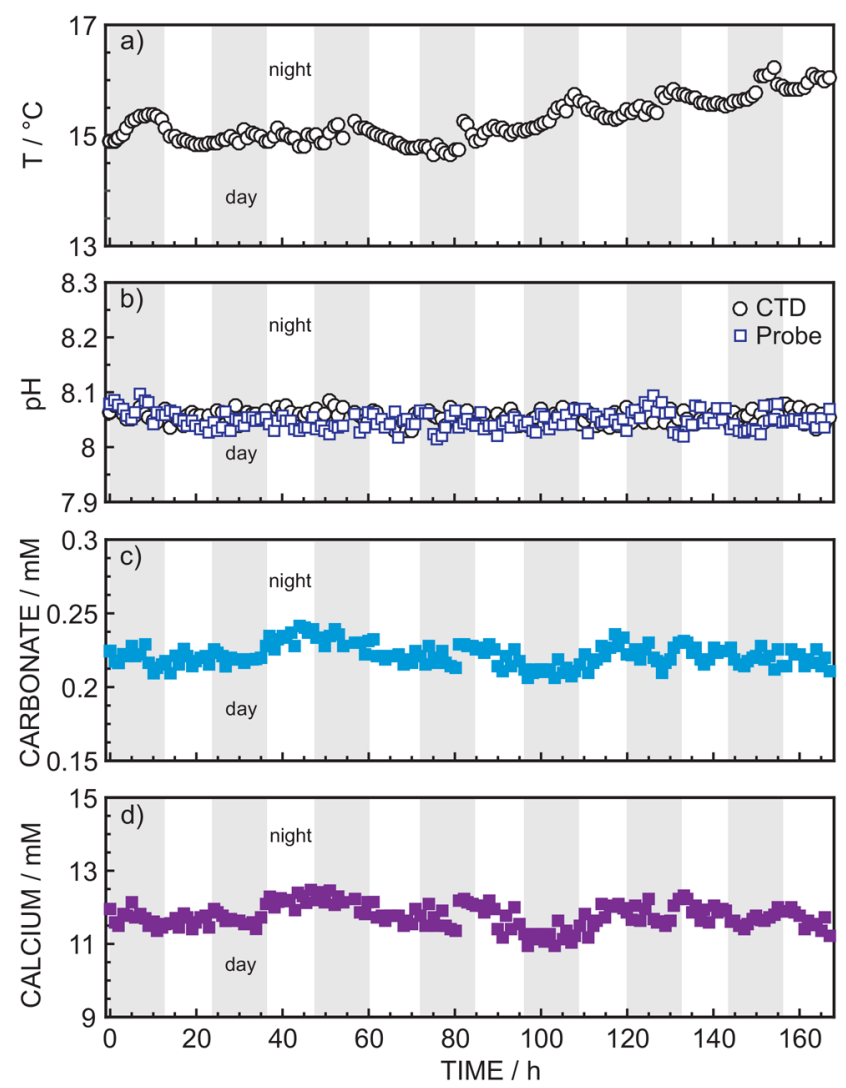

Figure 2. In situ profiles obtained for (a) temperature (CTD), (b) $\mathrm{pH}$ (CTD and developed electrodes), (c) carbonate, and (d) calcium during a 167 h deployment (from April 3, 2017, at 07:00 to April 10, 2017, at 12:00) in the CNR Station in Genoa Harbor (Italy). Note that additional sampling was performed for validation during the first $10 \mathrm{~h}$. The average salinity was 37.95 PSU. The deployment depth was $4.2 \mathrm{~m}$. The dissolved $\mathrm{O}_{2}$ concentration was $6.4 \pm 0.3 \mathrm{ppm}$, corresponding to $83.7 \pm 3.3 \%$ for oxygen saturation within the monitoring window. Light hours are shaded in gray. ${ }^{40}$

levels that are reached during the daylight hours and coinciding with temperature maxima. These day/night cycles are in accordance with the natural fluctuations of the carbon cycle, in which the absence of light causes $\mathrm{CO}_{2}$ production by the organisms. As the natural activity in a harbor is reduced compared with that of the open sea, ${ }^{32}$ note that the average dissolved $\mathrm{O}_{2}$ concentration $(6.4 \pm 0.3 \mathrm{ppm})$ corresponds to 83.7 $\pm 3.3 \%$ oxygen saturation, the increase in carbonate concentration during the night may be also related to an increase in the $\mathrm{CO}_{2}$ levels with a decrease in temperature. ${ }^{33}$ In addition, observed changes in carbonate levels are associated with calcium concentrations following exactly the same trends. The average concentrations of carbonate and calcium, $0.22 \pm 0.20$ and 11.82 $\pm 0.61 \mathrm{mmol} \mathrm{L}^{-1}$, are within the expected levels in seawater, ${ }^{18}$ and the molar percentage of carbonate with respect to calcium ( $\sim 2 \%)$ coincides with the carbonate speciation at the environmental $\mathrm{pH}$ as calcium is mainly associated with carbonate precipitation/dissolution processes. ${ }^{34,35}$ The variations observed in the $\mathrm{pH}$ profile are within $\pm 0.07 \mathrm{pH}$ unit, indicating no drastic changes. Good agreement with the results from the CTD is found.

In Situ Monitoring in Arcachon Bay (France). The submersible potentiometric probes were also tested in Arcachon Bay (France) by means of two different monitoring approaches: (i) a day/night cycle in the harbor with a duration of $14 \mathrm{~h}$ and (ii) the analysis of different locations along the freshwater effluent of the Eyre River in the bay during high tide. In both cases, the deployment was performed from a boat using a small crane. Importantly, the southwest corner of the bay is open to the sea, generating cycles of high and low tide thus leading to salinity cycles, which involves changes in the levels of key chemical species such as nutrients. ${ }^{36}$ For this reason, real-time monitoring of this area is significant for understanding (bio)geochemical processes locally occurring in the bay.

Observed profiles during the $14 \mathrm{~h}$ monitoring are presented in Figure 3 . With regard to the $\mathrm{pH}$ measurements, no drastic
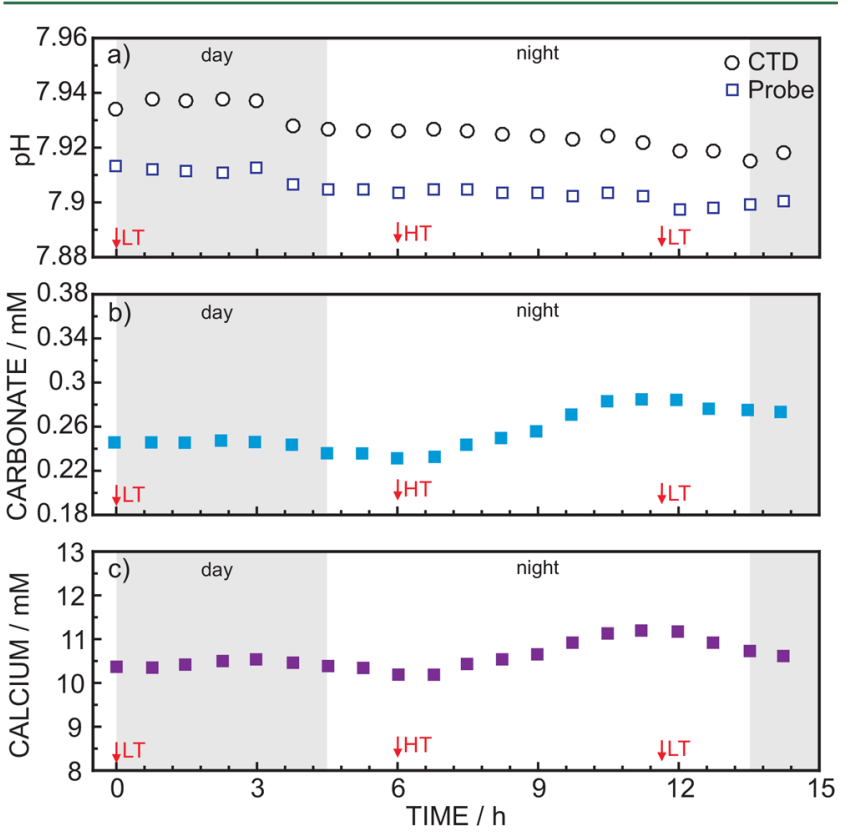

Figure 3. In situ profiles obtained for (a) $\mathrm{pH}$ (CTD and developed electrodes), (b) carbonate, and (c) calcium during a $16 \mathrm{~h}$ deployment (from May 17, 2017, at 17:00 to May 18, 2017, at 09:00) in Arcachon Harbor. The deployment depth was $1.5 \mathrm{~m}$. The local times for high and low tides (HT and LT, respectively) were determined according to the tidal record at Jetée d'Eyrac $\left(44^{\circ} 40^{\prime} \mathrm{N} 1^{\circ} 10^{\prime} \mathrm{W}\right)$ and considering the temporal evolution of the seawater level in the Arcachon basin. ${ }^{41,42}$ Light hours are shaded in gray. ${ }^{43}$

changes were observed, while as expected, variations of carbonate and calcium levels are related to the tidal cycles. Minimal concentrations coincide with high-tide conditions, while the maximum ones are found at low tides as a consequence of the higher freshwater effluent loading of carbonate species better known as the "tidal flushing" effect. ${ }^{37}$ Carbonate and calcium levels are slightly lower during the daylight hours, and the carbonate-to-calcium ratio is in agreement with the speciation. Moreover, the degree of seawater saturation $(\Omega)$ with respect to calcite and aragonite may be directly calculated from calcium and carbonate concentrations according to eq 4 :

$$
\Omega=\frac{{ }^{c_{\mathrm{Ca}}{ }^{c} \mathrm{Carb}}}{k_{\mathrm{sp}}}
$$

where the apparent solubility product $\left(k_{\mathrm{sp}}\right)$ refers to either calcite or aragonite. As observed in Figure S9, similar tidal trends were obtained and the calculated values ranged from 4.1 to 5.2 for calcite and from 2.8 to 3.5 for aragonite, when $k_{\mathrm{sp}}$ values of $5.94 \times$ $10^{-7}$ and $8.76 \times 10^{-7} \mathrm{~mol}^{2} \mathrm{~L}^{-2}$ (atmospheric pressure, $25^{\circ} \mathrm{C}$, and $34.5 \%$ salinity) were used respectively. ${ }^{38}$ Note that the 
Table 1. Results Obtained in Different Locations of Arcachon Bay (France) on May 18, 2017, Using the Submersible Device Incorporating the Multiparameter CTD ( $T$, salinity, dissolved $\mathrm{O}_{2}$, and $\left.\mathrm{pH}\right)$ Together with the Developed Potentiometric Probes for $\mathrm{pH}$, Calcium, and Carbonate ${ }^{a}$

\begin{tabular}{|c|c|c|c|c|c|c|c|c|c|c|c|}
\hline \multirow[b]{2}{*}{ location $^{b}$} & \multirow[b]{2}{*}{ hour } & \multirow[b]{2}{*}{$T\left({ }^{\circ} \mathrm{C}\right)$} & \multirow[b]{2}{*}{ PSU } & \multirow[b]{2}{*}{$\mathrm{DOXY}^{c}$} & \multicolumn{2}{|c|}{$\mathrm{pH}$} & \multicolumn{2}{|c|}{$\left[\mathrm{Ca}^{2+}\right](\mathrm{mM})$} & \multicolumn{3}{|c|}{$\left[\mathrm{CO}_{3}{ }^{2-}\right](\mathrm{mM})$} \\
\hline & & & & & CTD & in situ $^{d}$ & AAS & in situ $^{d}$ & $\mathrm{Sev}^{e}$ & macro ${ }^{f}$ & in situ $^{d}$ \\
\hline AHB & 9:03 & 17.8 & 32.1 & 6.92 & 7.92 & 7.90 & 10.82 & 10.81 & 0.31 & 0.30 & 0.28 \\
\hline \multirow[t]{2}{*}{ PM } & $10: 30$ & 17.9 & 33.1 & 7.66 & 8.00 & 7.98 & 10.97 & 10.98 & 0.32 & 0.32 & 0.30 \\
\hline & $10: 50$ & & & & & 7.98 & & 11.01 & & & 0.31 \\
\hline \multirow[t]{2}{*}{ LH } & $11: 45$ & 17.8 & 31.2 & 7.77 & 7.92 & 7.88 & 11.10 & 11.09 & 0.36 & 0.35 & 0.33 \\
\hline & $12: 05$ & & & & & 7.88 & & 11.10 & & & 0.33 \\
\hline \multirow[t]{3}{*}{ CG } & $12: 50$ & 17.8 & 31.1 & 7.81 & 7.90 & 7.88 & 11.23 & 11.20 & 0.38 & 0.38 & 0.37 \\
\hline & 13:11 & & & & & 7.87 & & 11.21 & & & 0.36 \\
\hline & $13: 36$ & & & & & 7.87 & & 11.19 & & & 0.36 \\
\hline
\end{tabular}

${ }^{a}$ Additional ex situ and on site measurements performed for validation are included (high tide at $\sim 11: 20$ and next low tide at $\sim 17: 00$ ). ${ }^{b}$ Abbreviations: $\mathrm{AHB}$, Arcachon Harbor $\left(44^{\circ} 39.652^{\prime} \mathrm{N} 1^{\circ} 09.050^{\prime} \mathrm{W}\right)$; PM, Pointe de la Matelle $\left(44^{\circ} 39.708^{\prime} \mathrm{N} 1^{\circ} 07.711^{\prime} \mathrm{W}\right)$; LH, La Hume $\left(44^{\circ} 39.750^{\prime} \mathrm{N} 1^{\circ} 06.709^{\prime} \mathrm{W}\right)$; CG, Chenal de Gujan $\left(44^{\circ} 39.409^{\prime} \mathrm{N} 1^{\circ} 05.114^{\prime} \mathrm{W}\right) .^{c}$ In parts per million. ${ }^{d}$ In situ measurements using the developed submersible device based on ISEs for $\mathrm{pH}$, calcium, and carbonate. ${ }^{e}$ Calculated from $\mathrm{TCO}_{2}$ (total $\mathrm{CO}_{2}$ ) obtained from on site potentiometric measurements using a Severinghaus probe. ${ }^{f}$ Obtained on site by using macroelectrodes analogous to those used into the submersible probe.

calculated values may vary because of the influence of temperature, pressure, and salinity on the values of $k_{\mathrm{sp}}$, and as far as we know, there are no universal equations to calculate these values depending on the environmental conditions. ${ }^{39}$ To the best of our knowledge, this is the first time that direct in situ measurements of calcium and carbonate have been accomplished in Arcachon Bay.

For the second monitoring, Table 1 shows the results of a physical displacement to the west along the bay while the salinity was not drastically fluctuating. While no drastic changes were observed for $\mathrm{pH}$, carbonate and calcium levels increased with westward displacement, in agreement with a higher freshwater content. Validation of the observed concentrations shows uncertainties of $<0.5 \%,<10 \%$, and $<0.3$ for $\mathrm{pH}$, carbonate, and calcium, respectively, confirming again the suitability of the developed sensors for in situ seawater analysis.

In summary, we have developed submersible potentiometric probes to detect $\mathrm{pH}$, carbonate, and calcium in seawater in an autonomous manner with rapid data acquisition. The environmental application is demonstrated in different aquatic areas of significance. The flow mode adopted for the measurements allows the correction of electrode drifts and makes it possible to integrate further in-line pretreatments as needed for the potentiometric detection of other relevant ions. ${ }^{28,29}$

\section{ASSOCIATED CONTENT}

\section{S Supporting Information}

The Supporting Information is available free of charge on the ACS Publications website at DOI: 10.1021/acs.estlett.7b00388.

Experimental section with materials, reagents, techniques, compositions of membranes, fabrication of the miniaturized electrodes (Figure S1), and the reference electrode, description of the submersible housing, protocol for in situ measurements, and data treatment; analytical performance of the sensors (Tables S1 and S2); validation of the sensors (Tables S3 and S4); calibration graphs (Figure S2); response to interfering ions (Figure S3); monitoring in Plentzia (Figure S4), and in Genoa Harbor (Figure S5); validation of in situ measurements (Figures S6-S8); and profiles for $\Omega$ (Figure S9) (PDF)

\section{AUTHOR INFORMATION}

\section{Corresponding Authors}

*E-mail: maria.cuartero@unige.ch. Phone: +41223796428.

*E-mail: eric.bakker@unige.ch. Phone: +41223796431.

ORCID

Maria Cuartero: 0000-0002-3858-8466

Gaston A. Crespo: 0000-0002-1221-3906

Eric Bakker: 0000-0001-8970-4343

Present Address

"G.A.C.: School of Chemical Science and Engineering, KTH Royal Institute of Technology, Stockholm, Sweden.

\section{Notes}

The authors declare no competing financial interest.

\section{ACKNOWLEDGMENTS}

The authors thank the Swiss National Science Foundation, the European Union (FP7-GA 614002-SCHeMA project) for the financial support of this research, and M-L. Tercier-Waeber, P. Povero, M. Castellano, C. Mirasole, J. Schafer, M. Abdou, and T. Gil-Diaz for field work.

\section{REFERENCES}

(1) Martz, T. R.; Daly, K. L.; Byrne, R. H.; Stillman, J. H.; Turk, D. Technology for Ocean Acidification Research Needs and Availability. Oceanography 2015, 25, 40-47.

(2) Wang, Z. A.; Sonnichsen, F. N.; Bradley, A. M.; Hoering, K. A.; Lanagan, T. M.; Chu, S. N.; Hammar, T. R.; Camilli, R. In Situ Sensor Technology for Simultaneous Spectrophotometric Measurements of Seawater Total Dissolved Inorganic Carbon and pH. Environ. Sci. Technol. 2015, 49, 4441-4449.

(3) Flecha, S.; Perez, F. F.; Garcia-Lafuente, J.; Sammartino, S.; Rios, A. F.; Huertas, I. E. Trends of $\mathrm{pH}$ decrease in the Mediterranean Sea through high frequency observational data: indication of ocean acidification in the basin. Sci. Rep. 2015, 5, 1-8.

(4) Bates, N. R.; Best, M. H. P.; Neely, K.; Garley, R.; Dickson, A. G.; Johnson, R. J. Detecting anthropogenic carbon dioxide uptake and ocean acidification in the North Atlantic Ocean. Biogeosciences 2012, 9 , 2509-2522.

(5) Choi, Y. S.; Lvova, L.; Shin, J. H.; Oh, S. H.; Lee, C. S.; Kim, B. H.; Cha, G. S.; Nam, H. Determination of oceanic carbon dioxide using a carbonate-selective electrode. Anal. Chem. 2002, 74, 2435-2440.

(6) Sun, X. L.; Higgins, J.; Turchyn, A. V. Diffusive cation fluxes in deep-sea sediments and insight into the global geochemical cycles of 
calcium, magnesium, sodium and potassium. Mar. Geol. 2016, 373, 6477.

(7) Jones, E. M.; Fenton, M.; Meredith, M. P.; Clargo, N. M.; Ossebaar, S.; Ducklow, H. W.; Venables, H. J.; de Baar, H.J. W. Ocean acidification and calcium carbonate saturation states in the coastal zone of the West Antarctic Peninsula. Deep Sea Res., Part II 2017, 139, 181-194.

(8) Yang, D. W.; Guo, J. J.; Liu, Q. S.; Luo, Z.; Yan, J. W.; Zheng, R. E. Highly sensitive Raman system for dissolved gas analysis in water. Appl. Opt. 2016, 55, 7744-7748.

(9) Tamburri, M. N.; Johengen, T. H.; Atkinson, M. J.; Schar, D. W. H.; Robertson, C. Y.; Purcell, H.; Smith, G. J.; Pinchuk, A.; Buckley, E. N. Alliance for Coastal Technologies: Advancing Moored pCO2 Instruments in Coastal Waters. Mar. Technol. Soc. J. 2011, 45, 43-51.

(10) Clarke, J. S.; Achterberg, E. P.; Connelly, D. P.; Schuster, U.; Mowlem, M. Developments in marine pCO2 measurement technology; towards sustained in situ observations. TrAC, Trends Anal. Chem. 2017, $88,53-61$.

(11) Ishiji, T.; Chipman, D. W.; Takahashi, T.; Takahashi, K. Amperometric sensor for monitoring of dissolved carbon dioxide in seawater. Sens. Actuators, B 2001, 76, 265-269.

(12) Tabacco, M. B.; Uttamlal, M.; McAllister, M.; Walt, D. R. An autonomous sensor and telemetry system for low-level pCO2 measurements in seawater. Anal. Chem. 1999, 71, 154-161.

(13) Wiegran, K.; Trapp, T.; Cammann, K. Development of a dissolved carbon dioxide sensor based on a coulometric titration. Sens. Actuators, $B$ 1999, 57, 120-124.

(14) Albaiges, J. Handbook of water analysis, 2nd edition. Int. J. Environ. Anal. Chem. 2008, 88, 598.

(15) Martz, T. R.; Jannasch, H. W.; Johnson, K. S. Determination of carbonate ion concentration and inner sphere carbonate ion pairs in seawater by ultraviolet spectrophotometric titration. Mar. Chem. 2009, $115,145-154$.

(16) Bockmon, E. E.; Dickson, A. G. An inter-laboratory comparison assessing the quality of seawater carbon dioxide measurements. Mar. Chem. 2015, 171, 36-43.

(17) Zhan, N.; Huang, Y.; Rao, Z.; Zhao, X. L. Fast Detection of Carbonate and Bicarbonate in Groundwater and Lake Water by Coupled Ion Selective Electrode. Fenxi Huaxue 2016, 44, 350-360.

(18) Cuartero, M.; Bakker, E. Environmental Water Analysis with Membrane Electrodes. Current Opinion in Electrochemistry 2017, n/a.

(19) Crespo, G. A. Recent Advances in Ion-selective membrane electrodes for in situ environmental water analysis. Electrochim. Acta 2017, 245, 1023.

(20) Dabrowska, S.; Migdalski, J.; Lewenstam, A. Direct Potentiometric Determination of Hydrogen Carbonate in Mineral Waters. Electroanalysis 2017, 29, 140-145.

(21) Xie, X.; Bakker, E. Non-Severinghaus potentiometric dissolved CO2 sensor with improved characteristics. Anal. Chem. 2013, 85, 13321336.

(22) Yuan, D. J.; Anthis, A. H. C.; Ghahraman Afshar, M.; Pankratova, N.; Cuartero, M.; Crespo, G. A.; Bakker, E. All-Solid-State Potentiometric Sensors with a Multiwalled Carbon Nanotube Inner Transducing Layer for Anion Detection in Environmental Samples. Anal. Chem. 2015, 87, 8640-8645.

(23) Pankratova, N.; Crespo, G. A.; Afshar, M. G.; Crespi, M. C.; Jeanneret, S.; Cherubini, T.; Tercier-Waeber, M. L.; Pomati, F.; Bakker, E. Potentiometric sensing array for monitoring aquatic systems. Environ. Sci-Proc. Imp 2015, 17, 906-914.

(24) Lueker, T. J.; Dickson, A. G.; Keeling, C. D. Ocean pCO2 calculated from dissolved inorganic carbon, alkalinity, and equations for $\mathrm{K}-1$ and K-2: validation based on laboratory measurements of $\mathrm{CO} 2$ in gas and seawater at equilibrium. Mar. Chem. 2000, 70, 105-119.

(25) Dickson, A. G.; Millero, F. J. A Comparison of the EquilibriumConstants for the Dissociation of Carbonic-Acid in Seawater Media. Deep-Sea Res., Part A 1987, 34, 1733-1743.

(26) Millero, F. J.; Graham, T. B.; Huang, F.; Bustos-Serrano, H.; Pierrot, D. Dissociation constants of carbonic acid in seawater as a function of salinity and temperature. Mar. Chem. 2006, 100 (1-2), 8094.
(27) Lee, K.; Millero, F. J.; Campbell, D. M. The reliability of the thermodynamic constants for the dissociation of carbonic acid in seawater. Mar. Chem. 1996, 55, 233-245.

(28) Cuartero, M.; Crespo, G. A.; Bakker, E. Tandem Electrochemical Desalination-Potentiometric Nitrate Sensing for Seawater Analysis. Anal. Chem. 2015, 87, 8084-8089.

(29) Pankratova, N.; Cuartero, M.; Cherubini, T.; Crespo, G. A.; Bakker, E. In-Line Acidification for Potentiometric Sensing of Nitrite in Natural Waters. Anal. Chem. 2017, 89, 571-575.

(30) Athavale, R.; Kokorite, I.; Dinkel, C.; Bakker, E.; Wehrli, B.; Crespo, G. A.; Brand, A. In Situ Ammonium Profiling Using SolidContact Ion-Selective Electrodes in Eutrophic Lakes. Anal. Chem. 2015, 87, 11990-11997.

(31) Bobacka, J.; Ivaska, A.; Lewenstam, A. Potentiometric ion sensors. Chem. Rev. 2008, 108, 329-351.

(32) Ruggieri, N.; Castellano, M.; Capello, M.; Maggi, S.; Povero, P. Seasonal and spatial variability of water quality parameters in the Port of Genoa, Italy, from 2000 to 2007. Mar. Pollut. Bull. 2011, 62, 340-349.

(33) Weiss, R. F. Carbon dioxide in water and seawater: the solubility of a non-ideal gas. Mar. Chem. 1974, 2, 203-215.

(34) Easley, R. A.; Patsavas, M. C.; Byrne, R. H.; Liu, X. W.; Feely, R. A.; Mathis, J. T. Spectrophotometric Measurement of Calcium Carbonate Saturation States in Seawater. Environ. Sci. Technol. 2013, 47, $1468-1477$.

(35) Chen, Y. M.; Zhang, L.; Xu, C. A.; Vaidyanathan, S. Dissolved inorganic carbon speciation in aquatic environments and its application to monitor algal carbon uptake. Sci. Total Environ. 2016, 541, 12821295.

(36) Deborde, J.; Anschutz, P.; Auby, I.; Gle, C.; Commarieu, M. V.; Maurer, D.; Lecroart, P.; Abril, G. Role of tidal pumping on nutrient cycling in a temperate lagoon (Arcachon Bay, France). Mar. Chem. 2008, 109, 98-114.

(37) Cook, D. O. Tidal Flushing in Beaches and coastal geology. Encyclopedia of Earth science; Springer: Seacaucus, NJ, 1982; pp 819820.

(38) Berner, R. T. The solubility of calcite and aragonite in seawater at atmospheric pressure and 34.5\%o Salinity. Am. J. Sci. 1976, 276, 713730.

(39) Edmond, J. M.; Gieskes, J. M. T. M. On the calculation of the degree of saturation of sea water with respect to calcium carbonate under in situ conditions. Geochim. Cosmochim. Acta 1970, 34, 1261-1291.

(40) https://www.timeanddate.com/sun/italy/genoa?month= 4\&year=2017 (accessed August 21, 2017).

(41) http://maree.info/136? d=20170517, Annuaire des maréesFrance (accessed July 3, 2017).

(42) http://maree.info/136?d=20170518, Annuaire des maréesFrance (accessed July 3, 2017).

(43) https://www.tutiempo.net/arcachon.html?datos=calendario\#cal, Mapa del tiempo (accessed July 14, 2017). 